\title{
SPECTROSCOPIC STUDY OF EFFECTS OF TETRAALKYLAMMONIUM CATIONS ON F-'-SENSING PROPERTIES OF CALIX[4]PYRROLE BORADIAZAINDACENE DYE
}

\author{
Yongjun Lv* \\ College of Material and Chemical Engineering, Sichuan University of Science and Engineering, Zigong, 643000, China
}

Recebido em 08/01/2016; aceito em 17/03/2016; publicado na web em 25/05/2016

\begin{abstract}
A novel meso-tetracyclohexylcalix[4]pyrrole-based boradiazaindacene dye $\mathbf{3}$ was synthesized and characterized. $\mathrm{F}^{-}$-binding properties of the dye in the presence of tetrabutylammonium $\left(\mathrm{TBA}^{+}\right)$, tetraethylammonium $\left(\mathrm{TEA}^{+}\right)$, and tetramethylammonium $\left(\mathrm{TMA}^{+}\right)$ counter ions were investigated by UV-Vis, fluorescence, and NMR spectroscopies. Dye 3 displayed various degrees of absorption red shift, fluorescence quenching, and downfield shifts of $\mathrm{NH}$ signals for the three fluoride salts. The association constants of these salts mainly depend on cation size effects and ion-pairing effects and were in the order $K_{\mathrm{TMA+}}>K_{\mathrm{TEA}+}>K_{\mathrm{TBA}+}$. Thus, we speculate that both $\mathrm{F}^{-}$and tetraalkylammonium cations are concomitantly located above and below a bowl-shaped calix[4]pyrrole cup in an ion-paired complex, respectively.
\end{abstract}

Keywords: calix[4]pyrrole; sensing; spectroscopy; cation size effect.

\section{INTRODUCTION}

Calix[4]pyrrole, as a pyrrole-derived macrocycle, was first reported as an efficient halide anion receptor by Sessler's group in 1996. ${ }^{1}$ Since then, calix[4]pyrrole-based receptors have attracted an increasing attention to modulate the anion-binding affinity and selectivity of the parent calix[4]pyrrole. ${ }^{2-6}$ In general, calix[4]pyrrole derivatives are prepared to sense halide anions through hydrogen bonds ${ }^{7,8}$ or the ion-pairing effect. ${ }^{9,10}$ In an anion-sensing process, tetrabutylammonium $\left(\mathrm{TBA}^{+}\right)$cation salts are readily utilized, yet the effects of various tetraalkylammonium cations have been largely ignored. Sessler and co-workers elucidated that cations of different sizes can affect the anion-binding affinity of calixpyrroles in the solid state. ${ }^{11}$ However, this effect in solution has not been studied in detail. As a result, we herein report the $\mathrm{F}^{-}$-binding properties of calix[4] pyrrole boradiazaindacene (BODIPY) in $\mathrm{CH}_{3} \mathrm{CN}$ solution using tetrabutylammonium fluoride (TBA-F), tetraethylammonium fluoride (TEA-F), and tetramethylammonium fluoride (TMA-F) salts. Their sensing properties were investigated by UV-Vis, fluorescence, and NMR spectroscopies. With the introduction of a BODIPY fluorophore on a calix[4]pyrrole, $\mathrm{F}^{-}$-recognition processes can be monitored by colorimetric and fluorometric dual-channel patterns. ${ }^{12-17}$

\section{EXPERIMENTAL}

\section{Materials and methods}

All reagents were commercially obtained and used without further purification. In titration experiments, $\mathrm{F}^{-}$was added in the form of $\mathrm{TBA}^{+}, \mathrm{TEA}^{+}$, and $\mathrm{TMA}^{+}$salts. The fluoride salts were purchased from Alfa Aesar and were stored in a desiccator under vacuum. Chromatography-grade $\mathrm{CH}_{3} \mathrm{CN}$ was used. ${ }^{1} \mathrm{H} \mathrm{NMR}$ and ${ }^{13} \mathrm{C} \mathrm{NMR}$ spectra were obtained using a Varian $400 \mathrm{MHz}$ INOVA spectrometer with the samples dissolved in $\mathrm{CDCl}_{3}$. ESI-MS spectra were obtained using a Waters Micromass ZQ-4000 mass spectrometer. C, $\mathrm{H}, \mathrm{N}$ elemental analyses were performed using Vario-EL. UV-Vis spectra were obtained using a PerkinElmer Lambda 35 spectrometer. Fluorescence spectra were obtained using a PerkinElmer LS55

\footnotetext{
*e-mail: yongjunlv@qq.com
}

spectrometer. All experiments were conducted at room temperature $\left(25^{\circ} \mathrm{C}\right)$. A solution of BODIPY dye $3\left(1.1 \times 10^{-3} \mathrm{~mol} \mathrm{~L}^{-1}\right)$ in $\mathrm{CH}_{3} \mathrm{CN}$ was prepared and diluted to a concentration appropriate for UV-Vis and fluorescence spectroscopies; the appropriate $\mathrm{F}^{-}$salt (TBA-F, TEA-F, or TMA-F) dissolved in $\mathrm{CH}_{3} \mathrm{CN}$ was added to attain the $\mathrm{F}^{-}$concentration of $1.1 \times 10^{-2} \mathrm{~mol} \mathrm{~L}^{-1}$, and the absorption/emission spectra of the resulting solution were immediately obtained. Nonlinear curves were fit to the absorption and fluorescence data and were expressed as equations (1) and (2), respectively. ${ }^{18}$

$$
\begin{aligned}
& A=A_{0}+0.5 \Delta \varepsilon\left\{C_{D}+C_{F}+\frac{1}{K}-\left[\left(C_{D}+C_{F}+\frac{1}{K}\right)^{2}-4 C_{D} C_{F}\right]^{\frac{1}{2}}\right\} \\
& \frac{F I}{F I_{0}}=1+\left(\frac{F I_{\max }}{2 F I_{0}}-\frac{1}{2}\right)\left\{1+\frac{C_{F}}{C_{D}}+\frac{1}{K C_{D}}-\left[\left(1+\frac{C_{F}}{C_{D}}+\frac{1}{K C_{D}}\right)^{2}-4 \frac{C_{F}}{C_{D}}\right]^{\frac{1}{2}}\right\}
\end{aligned}
$$

where $A$ and $A_{0}$ are the absorbance of dye $\mathbf{3}$ in the presence and absence of $\mathrm{F}^{-}$, respectively, $F I$ and $F I_{0}$ are their corresponding fluorescence intensities, $C_{F}$ and $C_{D}$ are the concentrations of $\mathrm{F}^{-}$and dye $\mathbf{3}$, respectively, and $K$ is the association constant.

Synthesis of 3-[2-( $\beta$-tetracyclohexylcalix[4]pyrrolyl)ethenyl]4,4-difluoro-8-(4-bromo)phenyl-1,5,7-trimethyl-3a,4a-diaza-4bora-s-indacene (3)

Targeted dye 3 was prepared as shown in Scheme 1. Compound $\mathbf{1}^{19}(0.91 \mathrm{~g}, 2.00 \mathrm{mmol})$ and formylcalix[4]pyrrole 2 (1.23 g, $\left.2 \mathrm{mmol}\right)$ were refluxed in a mixture of dry toluene $(50 \mathrm{~mL})$, piperidine $(0.5$ $\mathrm{mL})$, and $\mathrm{AcOH}(0.5 \mathrm{~mL})$. The mixture was heated for $10 \mathrm{~h}$ in a Dean-Stark apparatus to azeotropically remove any water formed. The solvents were removed under reduced pressure, and the product was purified by column chromatography $\left(\mathrm{CH}_{2} \mathrm{Cl}_{2} /\right.$ hexane, $\left.1: 1\right)$ to obtain 3 as a purple solid $\left(0.70\right.$ g). Yield: $35 \%$. M.p. $>300{ }^{\circ} \mathrm{C}$. ESIMS: $m / z=1001.3\left(\mathrm{M}+\mathrm{H}^{+}\right) .{ }^{1} \mathrm{H}$ NMR $\left(400 \mathrm{MHz}, \mathrm{CDCl}_{3}\right) \delta: 1.42(\mathrm{~s}$, $\left.6 \mathrm{H}, \mathrm{CH}_{3}\right), 1.49\left(\mathrm{~m}, 30 \mathrm{H}, \mathrm{CH}_{2}\right), 2.00\left(\mathrm{~m}, 10 \mathrm{H}, \mathrm{CH}_{2}\right), 2.60\left(\mathrm{~s}, 3 \mathrm{H}, \mathrm{CH}_{3}\right)$, 5.88-6.00 (m, 7H, pyrrolic $\mathrm{CH}), 5.91-5.94(\mathrm{~m}, 2 \mathrm{H}$, pyrrolic $\mathrm{CH}), 5.96$ (d, $3.2 \mathrm{~Hz}, 2 \mathrm{H}$, pyrrolic CH), 6.40 (d, $J=2.4 \mathrm{~Hz}, 1 \mathrm{H}, \mathrm{NH}), 6.49$ (s, $1 \mathrm{H}, \mathrm{NH}), 7.16(\mathrm{~s}, 2 \mathrm{H}, 2 \mathrm{NH}), 7.18-7.24(\mathrm{~m}, 2 \mathrm{H}, 1 \mathrm{H}$ for vinylic, $1 \mathrm{H}$, 


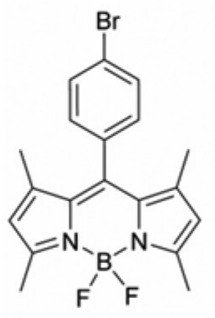

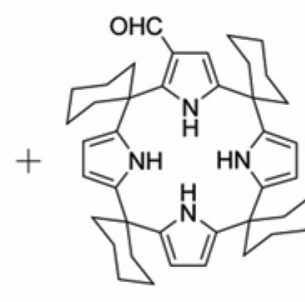

2
Scheme 1. Synthetic procedure for dye 3

$\mathrm{CH}), 7.63-7.67$ (m, 3H, $2 \mathrm{H}$ for $\mathrm{ArH}, 1 \mathrm{H}$ for vinylic). ${ }^{13} \mathrm{C}$ NMR (100 $\left.\mathrm{MHz}, \mathrm{CDCl}_{3}\right) \delta: 14.7,14.7,15.0,115.8,116.9,117.8,121,4,123.3$, 129.3, 129.4, 130.1, 132.4, 134.1, 136.5, 138.3, 142.1, 142.4, 142.5, 153.8, 153.8, 155.1, 156.7. Anal. calcd. for $3\left(\mathrm{C}_{60} \mathrm{H}_{68} \mathrm{BBrF}_{2} \mathrm{~N}_{6}\right): \mathrm{C}$, 71.93; H, 6.84; N, 8.39. Found: C, 71.96; H, 6.90; N, 8.34.

\section{RESULTS AND DISCUSSION}

\section{UV-Vis spectral studies}

Figure 1 shows changes in the UV-Vis spectra of $\mathbf{3}\left(1.1 \times 10^{-5} \mathrm{~mol}\right.$ $\mathrm{L}^{-1}$ ) upon titration with the $\mathrm{CH}_{3} \mathrm{CN}$ solution of TBA-F. Dye 3 exhibits a typical absorption band at $590 \mathrm{~nm}$; this band is red shifted by $90 \mathrm{~nm}$ compared to the corresponding band of parent BODIPY $1\left(\lambda_{\mathrm{ab}}=499\right.$ $\mathrm{nm})$. This absorption shift is attributed to the extension of $\pi$-electron conjugation systems with the modification of the calixpyrrole unit on the BODIPY core. ${ }^{20}$ With the stepwise addition of TBA-F, the absorbance intensity at $590 \mathrm{~nm}$ decreased and a new band gradually appeared at $609 \mathrm{~nm}$. The color correspondingly changed from fuchsia to blue (Figure 1 inset). These observed changes were attributed to the activated intramolecular charge transfer (ICT) process by $\mathrm{F}^{-}$ binding. ${ }^{21}$ Interestingly, adding TEA-F and TMA-F caused similar changes in the UV-Vis spectra and color of the solution, as evident in Figures $1 \mathrm{~S}$ and $2 \mathrm{~S}$ (Supplementary Material). However, on a per molar basis, the addition of TMA-F caused the greatest absorption band red shift, followed by the red shifts caused by the additions of TEA-F and TMA-F. On the basis of the UV-Vis data, we determined the association constants $K$ (Figure 1 inset), ${ }^{22}$ the results are shown in Table 1. The $\mathrm{F}^{-}$-binding order is $K_{\mathrm{TMA+}}>K_{\mathrm{TEA}+}>K_{\mathrm{TBA}+}$, opposite the order of their size. Specifically, $\mathrm{TMA}^{+}$, as a relatively small cation, is prone to associate with an electron-rich bowl-shaped cavity of the calix[4]pyrrole unit. This good match between the cation size and cavity would promote strong hydrogen bonding interactions between four pyrrolic hydrogen atoms and fluoride ions. ${ }^{23}$

\section{Fluorescence studies}

The fluorescence spectrum of dye $\mathbf{3}$ exhibits a typical emission

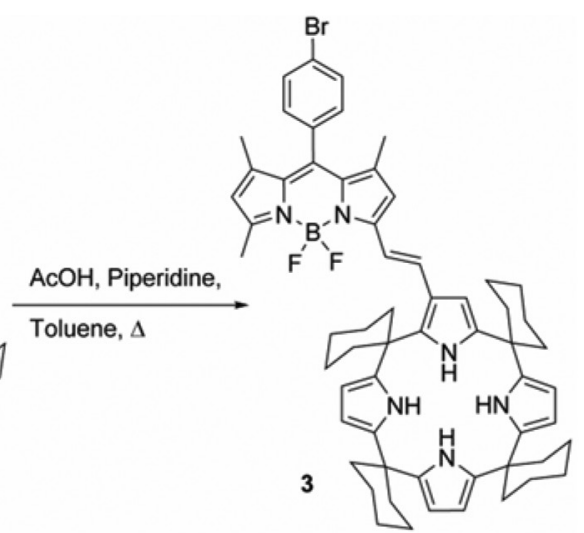

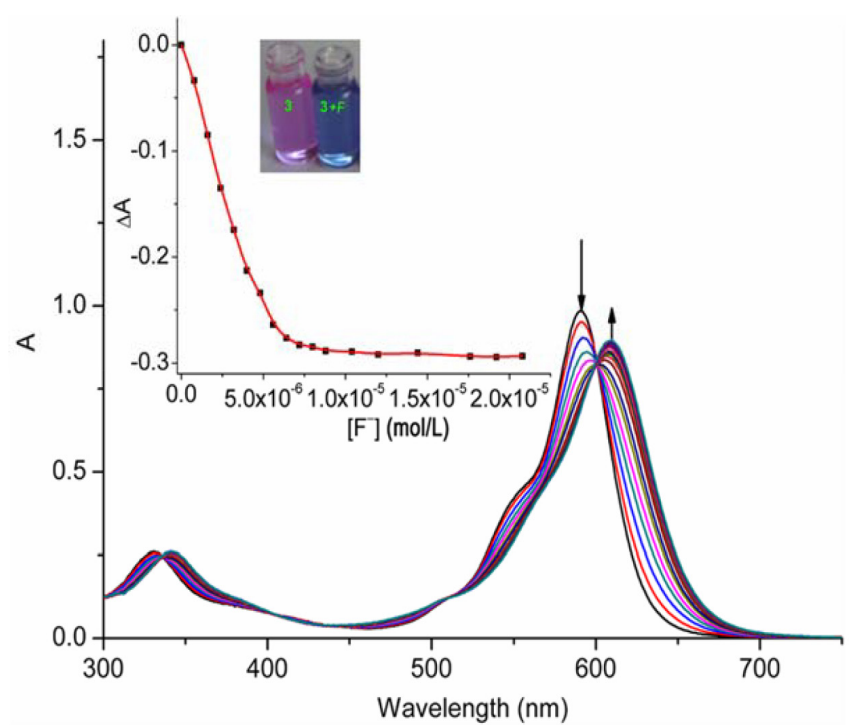

Figure 1. UV-Vis spectra of $3\left(1.1 \times 10^{-5} \mathrm{~mol} \mathrm{~L}^{-1}\right)$ in $\mathrm{CH}_{3} \mathrm{CN}$ upon the addition of TBA-F from 0 to $2.1 \times 10^{-5} \mathrm{~mol} \mathrm{L^{-1 }}$. Inset: nonlinear curve fitting as a function of $\left[F^{-}\right]$monitored at $591 \mathrm{~nm}$

band at $623 \mathrm{~nm}$, as shown in Figure 2. The quantum yield was determined to be 0.04 using rhodamine $\mathrm{B}(\Phi=0.49$ in EtOH $)$ as a standard. ${ }^{24}$ Compared to the emission wavelength of parent BODIPY $\mathbf{1}\left(\lambda_{\mathrm{em}}=510 \mathrm{~nm}\right)$, that of $\mathbf{3}$ exhibits a red shift of approximately 110 $\mathrm{nm}$, which reveals the ICT nature of the excited states of $\mathbf{3}$. The addition of TBA-F resulted in obvious fluorescence quenching at $623 \mathrm{~nm}$ and a 20-nm blue shift; these sensing events instantaneously occurred upon the addition of $\mathrm{F}^{-}$(Figure 2 inset). The disappearance of red fluorescence is ascribed to the occurrence of an ICT process from an electron-rich calix[4]pyrrole unit upon binding $\mathrm{F}^{-}$to an electrondeficient BODIPY group. The blue shift may be due to a slight twist of the conjugated pyrrole BODIPY plane after the coordination of $\mathrm{F}^{-}$, which affects the co-planarity of the entire structure of molecule $3 .^{25}$

The additions of TEA-F and TMA-F induced similar fluorescence changes (Figures 3S and 4S, Supplementary Material). However,

Table 1. Association constants and detection limits for $\mathbf{3}$ with $\mathrm{F}^{-}$as different tetraalkylammonium salts in $\mathrm{CH}_{3} \mathrm{CN}$

\begin{tabular}{lccc}
\hline Fluoride salt & $\begin{array}{c}K\left(\mathrm{~L}^{-1} \mathrm{~mol}\right) \text { determined by } \\
\text { UV-Vis spectra at } 590 \mathrm{~nm}\end{array}$ & $\begin{array}{c}K\left(\mathrm{~L}^{-1} \text { mol) determined by }\right. \\
\text { fluorescence at } 623 \mathrm{~nm}\end{array}$ & \multicolumn{2}{c}{ Detection limit (mol L-1) } \\
\hline TBA-F & $8.00 \times 10^{3}$ & $9.29 \times 10^{3}$ & $3.34 \times 10^{-5}$ \\
TEA-F & $1.32 \times 10^{4}$ & $1.12 \times 10^{4}$ & $2.76 \times 10^{-5}$ \\
TMA-F & $8.84 \times 10^{4}$ & $6.26 \times 10^{4}$ & $4.94 \times 10^{-6}$ \\
\hline
\end{tabular}


quenching exhibited the trend $\mathrm{TBA}^{+}<\mathrm{TEA}^{+}<\mathrm{TMA}^{+}$on a per molar basis. This order is related to the structure of tetraalkylammonium cations and to the affinity of $\mathbf{3}$ for fluoride. Similarly, association constants were also determined using equation (2), and lower detection limits were determined as three times the signal-to-noise ratio; the results are reported in Table $1 .{ }^{26}$ As reported in the table, good agreement is observed between $K$ values and those obtained from UV-Vis analyses. Fluorescence titrations indicated that $\mathbf{3}$ demonstrates a stronger affinity for TMA-F compared with the other two fluoride salts.

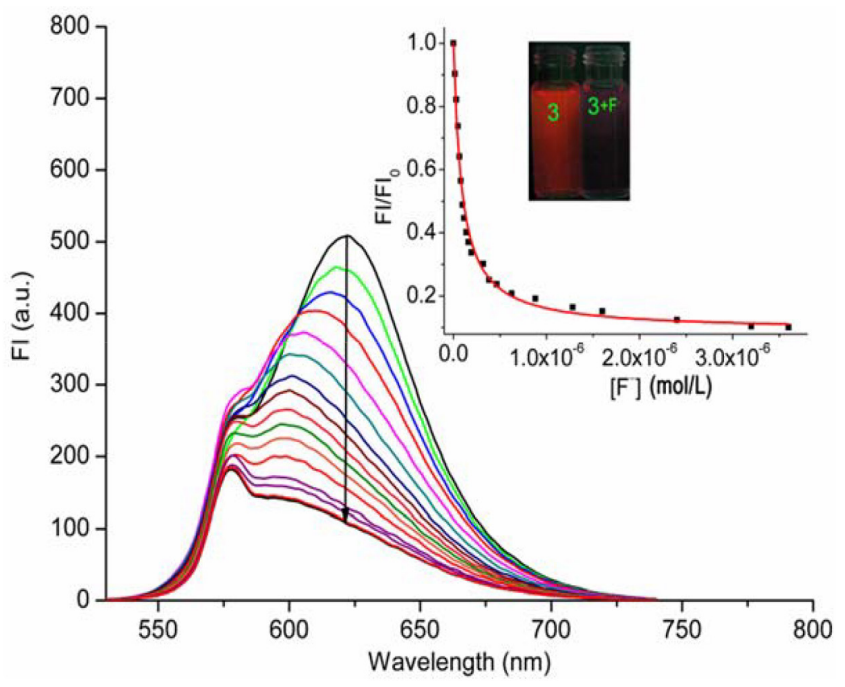

Figure 2. Fluorescence spectra of $3\left(1.1 \times 10^{-6} \mathrm{~mol} \mathrm{~L}^{-1}\right)$ in $\mathrm{CH}_{3} \mathrm{CN}$ upon

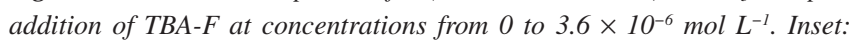
nonlinear curve fitting as a function of $\left[\mathrm{F}^{-}\right]$monitored at $623 \mathrm{~nm}$. Excitation was at $580 \mathrm{~nm}$

\section{${ }^{1}$ H NMR spectral studies}

The interactions of $\mathbf{3}$ with $\mathrm{F}^{-}$were further validated by ${ }^{1} \mathrm{H}$ NMR experiments. Figure 3 shows partial spectra of $\mathbf{3}$ upon the addition of 2.0 equivalents of $\mathrm{F}^{-}$with different cations. The signals of $\mathrm{NH}$ protons at $6.40,6.49$, and $7.16 \mathrm{ppm}$ disappeared, and downfield shifted to various degrees, which suggests the formation of a $3-\mathrm{F}^{-}$ hydrogen-bonding complex. The signals of the NH proton shifted to 12.42 and $12.92 \mathrm{ppm}$ for TBA-F, 12.50 and $13.02 \mathrm{ppm}$ for TEA-F, and 12.54 and 13.08 ppm for TMA-F. The downfield shifts also followed this order. As a result, we can reasonably speculate about the proposed interaction model of $\mathbf{3}$ and tetraalkylammonium

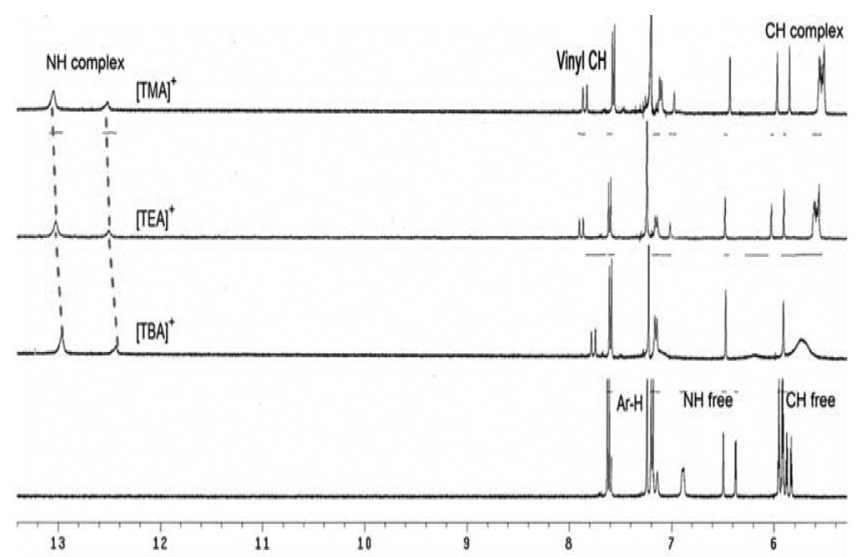

Figure 3. Partial ${ }^{1} \mathrm{H} N \mathrm{NM}$ spectra of $3\left(1.1 \times 10^{-2} \mathrm{~mol} \mathrm{~L}^{-1}\right)$ in $\mathrm{CDCl}_{3}$ and in the presence of 2.0 equivalents of $\mathrm{F}^{-}$as $T B A^{+}, T E A^{+}$, and $T M A^{+}$salts

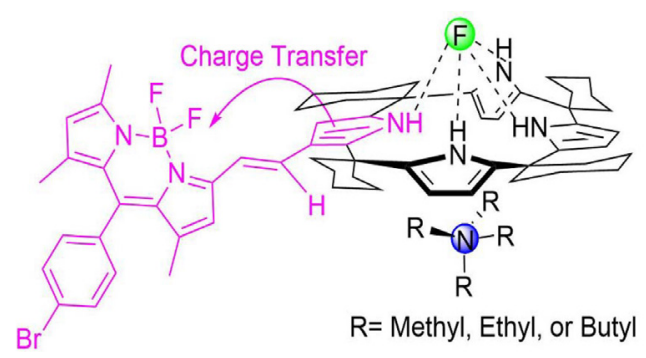

Figure 4. Proposed interaction model of 3 and tetraalkylammonium fluoride salts

fluoride salts (Figure 4). The $\mathrm{F}^{-}$and tetraalkylammonium cations were concomitantly located above and below the bowl-shaped calix[4]pyrrole cup. The formation of an ion-pairing complex may be based on a stepwise binding mechanism, whereby a calix[4]pyrrole subunit binds the $\mathrm{F}^{-}$anion initially to form a cone-conformation anionic complex with an electron-rich cavity opposed to the bound $\mathrm{F}^{-}$. The short distance between the $\mathrm{F}^{-}$ion and $\mathrm{N}$ atom in the cation would afford a close-contact ion-pairing arrangement. The hydrogen bonding interaction and affinity of $\mathbf{3}$ for $\mathrm{F}^{-}$would increase..$^{27-29}$ Therefore, $\mathrm{TMA}^{+}$, as the smallest quaternary ammonium cation among those tested, was found to induce substantial spectroscopic responses in the $\mathrm{F}^{-}$recognition process of dye $\mathbf{3}$.

\section{CONCLUSIONS}

We investigated the $\mathrm{F}^{-}$-binding properties of a calix[4]pyrrole BODIPY 3 in the presence of $\mathrm{TBA}^{+}, \mathrm{TEA}^{+}$, and $\mathrm{TMA}^{+}$as counter ions. Upon the addition of $\mathrm{F}^{-}$, the UV-Vis wavelength of the maximum absorption of $\mathbf{3}$ exhibited a $90-\mathrm{nm}$ red shift, the color of the solution changed from fuchsia to purple, fluorescence was quenched, and pyrrole NH signals in the ${ }^{1} \mathrm{H}$ NMR spectrum shifted downfield. Sensing responses were attributed to the ICT process from the electron-rich calix[4]pyrrole to electron-withdrawing BODIPY core. Moreover, the trend of association constants was $K_{\mathrm{TMA}+}>K_{\mathrm{TEA}+}>$ $K_{\mathrm{TBA}}$, which is a consequence of the magnitude of cation size effects and ion-pairing effects. Specifically, ion-pairing interactions can cooperatively strengthen hydrogen bonds, which would contribute to enhancing the affinity of $\mathbf{3}$ toward $\mathrm{F}^{-}$anions. Studies of the effects of tetraalkylammonium cations combined with other anions such as $\mathrm{Cl}^{-}, \mathrm{Br}^{-}, \mathrm{I}^{-}, \mathrm{H}_{2} \mathrm{PO}_{4}^{-}$, and $\mathrm{AcO}^{-}$are currently underway.

\section{ACKNOWLEDGMENTS}

This work was supported by the Foundation of Sichuan Educational Committee (No. 16ZA0260), the Scientific Research Fund of Sichuan University of Science and Engineering (No. 2012RC02), and the Sichuan Province Science and Technology Innovation Talent Project (No. 2015026).

\section{SUPPLEMENTARY MATERIAL}

$\mathrm{UV}-$ Vis spectra and fluorescence spectra of $\mathbf{3}$ in $\mathrm{CH}_{3} \mathrm{CN}$ upon the addition of TEA-F and TMA-F are available. Supplementary material associated with this article can be found, in the online version, at http://www.quimicanova.sbq.org.br/.

\section{REFERENCES}

1. Gale, P. A.; Sessler, J. L.; Lynch, K. V.; J. Am. Chem. Soc. 1996, 118, 5140

2. Kim, D. S.; Sessler, J. L.; Chem. Soc. Rev. 2015, 44, 532. 
3. Chang, K. C.; Minami, T.; Koutnik, P.; Savechenkov, P. Y.; Liu, Y.; Anzenbacher, P. J.; J. Am. Chem. Soc. 2014, 136, 1520.

4. Liu, Y.; Minami, T.; Nishiyabu, R.; Wang, Z.; Anzenbacher, P. J.; J. Am. Chem. Soc. 2013, 135, 7705.

5. Kim, S. K.; Gross, D. E.; Cho, D. G.; Lynch, V. M.; Sessler, J. L.; J. Org. Chem. 2011, 76, 1005.

6. Nielsen, K. A.; Cho, W. S.; Lyskawa, J.; Levillain, E.; Lynch, V. M.; Sessler, J. L.; Jeppesen, J. O.; J. Am. Chem. Soc. 2006, 128, 2444.

7. Choi, J. H.; Cho, D. G.; Tetrahedron. Lett. 2013, 54, 6928.

8. Yoon, J.; Kim, M. S.; Hong, S. J.; Sessler, J. L.; Lee, C. H.; J. Org. Chem. 2009, 74, 1065.

9. Kim, S. K.; Sessler, J. L.; Acc. Chem. Res. 2014, 47, 2525.

10. Kim, S. K.; Sessler, J. L.; Chem. Soc. Rev. 2010, 39, 3784.

11. Sessler, J. L.; Gross, D. E.; Cho, W. S.; Lynch, V. M.; Schmidtchen, F. P.; Bates, G. W.; Light, M. E.; Gale, P. A.; J. Am. Chem. Soc. 2006, 128, 12281.

12. Lv, Y.; Xu, J.; Guo, Y.; Shao, S.; Chem. Pap. 2011, 65, 553.

13. Lv, Y.; Xu, J.; Guo, Y.; Shao, S.; J. Inclusion Phenom. Macrocyclic Chem. 2012, 72, 95.

14. Gotor, R.; Costero, A. M.; Gacina, P.; Gil, S.; Parra, M.; Eur. J. Org. Chem. 2013, 2013, 1515.

15. Taner, B.; Kursunlu, A. N.; Güler, E.; Spectrochim. Acta, Part A 2014, 118, 903.

16. Kursunlu, A. N.; Sahin, E.; Güler, E.; RSC Adv. 2015, 5, 5951.
17. Kursunlu, A. N.; RSC Adv. 2015, 5, 41025.

18. Liu, W.; Xu, L.; Sheng, R.; Wang, P.; Li, H.; Wu, S.; Org. Lett. 2007, 9 , 3829.

19. Zhang, X.; Xiao, Y.; Qian, X.; Org. Lett. 2008, 10, 29.

20. Louder, A.; Burgess, K.; Chem. Rev. 2007, 107, 4891.

21. Baruah, M.; Qin, W.; Flors, C.; Hofkens, J.; Vallee, R. A.; Beljonne, D.; Auweraer, M. V.; Borggraeve, W. M.; Boens, N.; J. Phys. Chem. A 2006, 110, 5998.

22. Connors, K. A.; Binding Constants: The Measurement of Molecular Complex Stability, Wiley-VCH: New York, 1987.

23. Bates, G. W.; Gale, P. A.; Light, M. E.; CrystEngComm. 2006, 8, 300.

24. Almonasy, N.; Neoras, M.; Hykova, S.; Lycka, A.; Cermak, J.; Dvorak, M.; Michl, M.; Dyes Pigm. 2009, 82, 164.

25. Valeur, B.; Molecular Fluorescence, Principles and Applications, WileyVCH: New York, 2002.

26. Shortreed, M.; Kopelman, R.; Kuhn, M.; Hoyland, B.; Anal. Chem. 1996, 68, 1414.

27. Park, I. W.; Yoo, J.; Kim, B.; Adhikari, S.; Kim, S. K.; Yeon, Y.; Haynes, C. J. E.; Sutton, J. L.; Tong, C. C.; Lynch, V. M.; Sessler, J. L.; Gale, P. A.; Lee, C. H.; Chem.-Eur. J. 2012, 18, 2514.

28. Park, I. W.; Yoo, J.; Adhikari, S.; Parl, J. S.; Sessler, J. L.; Lee, C. H.; Chem.-Eur. J. 2012, 18, 15073.

29. Ciardi, M.; Tancini, F.; Gil-Ramirez, G.; Adan, E. C. E.; Massera, C.; Dalcanale, E.; Balester, P.; J. Am. Chem. Soc. 2012, 134, 13121. 